\title{
Inserting retention plastic caps to ball implant supported overdenture: easy chair side technique
}

\begin{abstract}
Traditionally, retention plastic caps are fitted to ball implant supported overdenture by the indirect method following the traditional prosthetic steps for implant over dentures. Drawbacks of this technique are more evident, such as improper load distribution between implant and mucoperiosteal denture foundation, pivoting effect at implant site resulting in frequent fracture of over denture at this site, loosening of the implant and time consuming and expensive as it needs extra laboratory steps and equipments. The aim of the present work was to present a simplified direct technique, which did not need any special equipments and hopping that it would avoid the disadvantages of the indirect one.
\end{abstract}

Keywords: overdenture, implants, occlusal forces, osseo integration, stabilization, residual ridges

\author{
Volume 2 Issue 5 - 2015
}

\author{
Nagy Abdul Samee Abdul Hameed \\ Misr University for Science \& Technology, Egypt \\ Correspondence: Nagy Abdul-Samee Abdul-Hameed,Vice \\ Dean for Graduate Studies \& Researches, College of Oral and \\ Dental Medicine, Misr University for Science \& Technology, Al- \\ Motamayez District, 77, Giza, Egypt, Tel 201000000000, \\ Email nagyabdulsamee@gmail.com
}

Received: June 20, 2015 | Published: July 25, 2015

\section{Introduction}

Restoration of totally edentulous patients with removable prosthesis designs that incorporate osseo integrated implants provides the patient with alternatives to mucosa-supported complete denture. ${ }^{1}$ A highly predictable and effective approach is the implantsupported over denture, which offers improved retention, stability, function, proprioception, and comfort. ${ }^{2,3}$ Compared with complete denture, implant-supported overdenture improves the stability of the prosthesis. Increased number of implants may guarantee more retention. However, there is a problem of increased cost and anatomical limitations in severely restored residual ridges, especially in the mandible. Several studies demonstrated that the two-implantssupported overdenture therapy can be considered as a very reliable treatment for patients with an edentulous mandible. ${ }^{4-6}$ Therefore, two-implants-supported overdenture in the mandible should be the standard treatment modality for full edentulous patients suffering from discomfort with their conventional denture. ${ }^{4-6}$

Various attachments have been advocated for retaining overdentures to implants. Attachments are mechanical interlocking devices of different designs including splinting bars, ball and socket attachments and combinations of bars and attachments. ${ }^{7,8}$ All the retention approaches distribute occlusal forces through the over denture to the implants and the posterior edentulous ridges. ${ }^{9}$ The degree of load sharing that occurs depends on the specific system used. ${ }^{910}$ An ideal situation would exist if the load were shared so that no area would be overloaded. Because this ideal condition is probably unattainable, designs that tend to provide the most appropriate load transfer would be preferred. ${ }^{11}$ Compared with individual attachment, bar connectors provide a rigid support for over denture similar to that provided by fixed prostheses, guarantee a primary stabilization by splinting the implants, ${ }^{12}$ provide better retention, ${ }^{13}$ and reduce load transmitted to implant. ${ }^{14}$

Individual attachments are indicated mainly when the span between implants is too long and when insufficient interarch space exists to accommodate attachments on a bar..$^{14}$ Despite their advantages, it has been proved that incorporating attachments in prosthesis induces more stresses to the supporting structures.${ }^{14}$ However, the resilient ball and socket type appears to transfer the stresses in a favorable manner to the retaining structures. ${ }^{14}$ The resilient attachments are designed to provide some vertical movement and rotation of the denture base. This is intended to allow the sharing of occlusal forces between the abutment and the soft tissues. ${ }^{14}$ From a clinical point of view, it is claimed that a resilient retention mechanism for over denture fixation should be used to allow equal tissue and implant support. It protects against implant overloading (stress-breaking action) because most of the masticators stresses are transmitted to the posterior edentulous ridge.$^{12-18}$ Bone loss in the edentulous regions of mandible is not significantly reduced because of the resilient nature of the ball attachment permitting free rotation in six directions. ${ }^{10,14}$ Traditionally, retention plastic caps are fitted to ball implant supported over dentures by the indirect method. Drawbacks of this technique are more evident, such as improper load distribution between implant and mucoperiosteal denture foundation, pivoting effect at implant site resulting in frequent fracture of the overdenture in this site, loosening of the implant, and time consuming as it needs extra laboratory steps. Also during curing, the caps may be distorted as the curing temperature can approach the glass transition temperature of the polymer from which the caps are fabricated. This drew my attention to introduce a direct technique, which proved to be simpler, did not need special equipments, and hopping that it will eliminate the drawbacks of the indirect technique.

\section{Materials and methods}

\section{Abutment preparation}

a. Following successful osseo integration, the male parts of ball attachment are screwed into the abutments (Figure 1).

b. Orthodontic elastic rings (Figure 2) are used to block out the undercuts gingival to the ball attachment (Figure 3).

c. Retention plastic caps (Figure 4) are fitted to abutments either manually or better by the help of ligature gun (Figure 5). This preparation is repeated before every clinical step during denture construction. 


\section{Over denture construction}

After abutment preparation (Figure 6) the conventional clinical and laboratory procedures for denture construction (Figure 7-14) are followed except that metal framework should not cover the abutment areas.

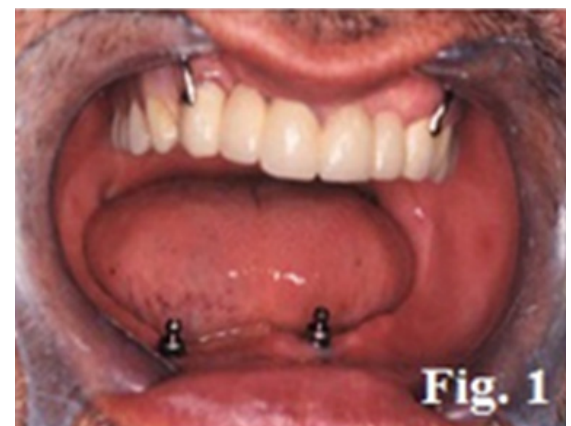

Figure I Two ball attachments seated on osseo integrated implant fixtures.

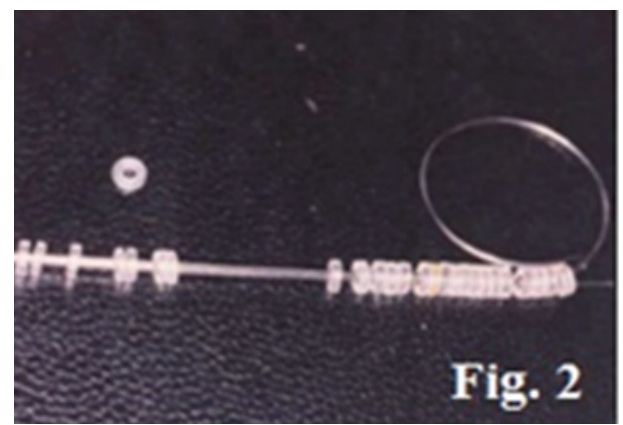

Figure 2 Orthodontic elastic rings used to block out undercuts made by abutment's neck.

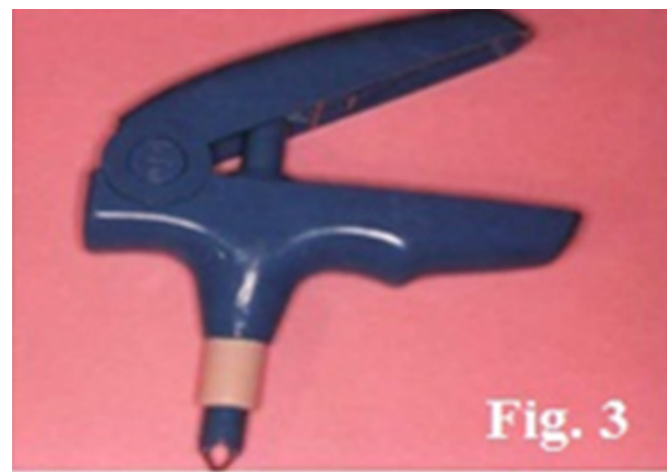

Figure 3 Orthodontic elastic rings are inserted.

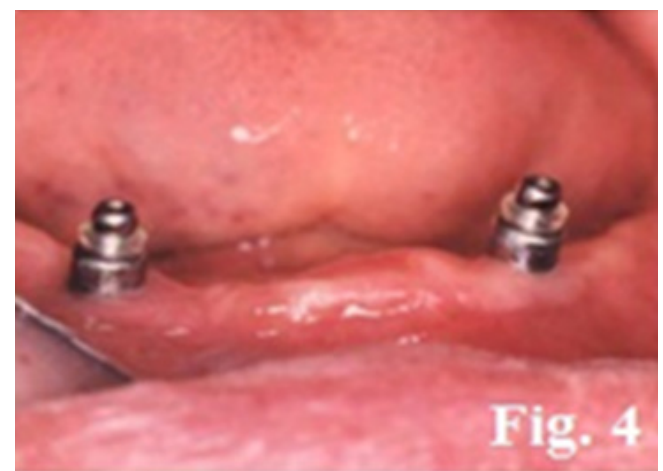

Figure 4 Retention plastic caps.

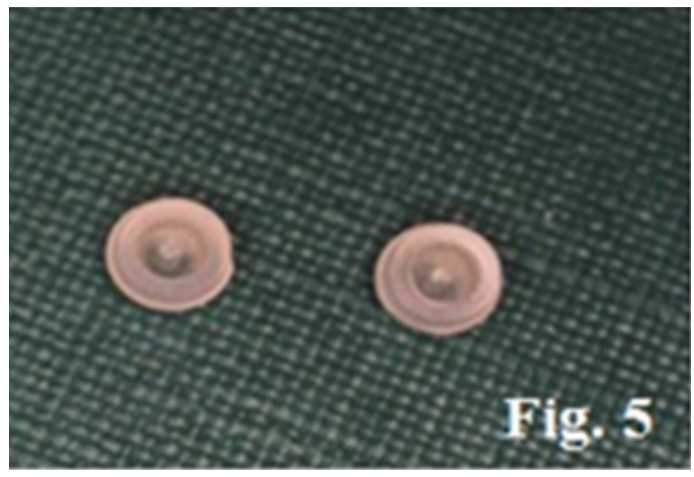

Figure 5 Ligature gun.

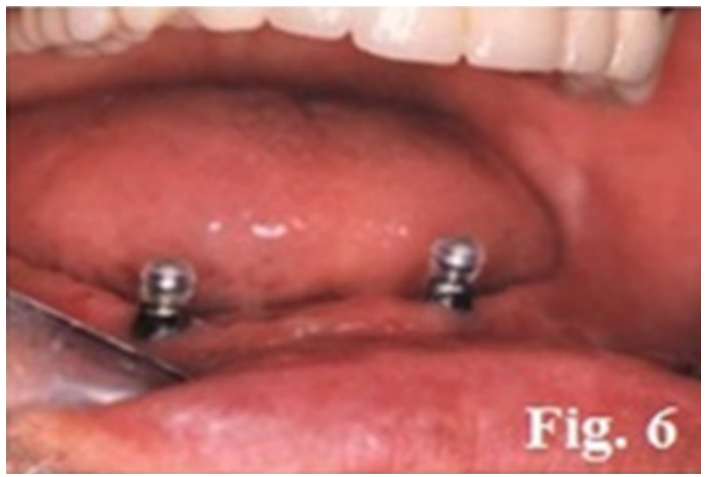

Figure 6 Retention plastic caps are in place.

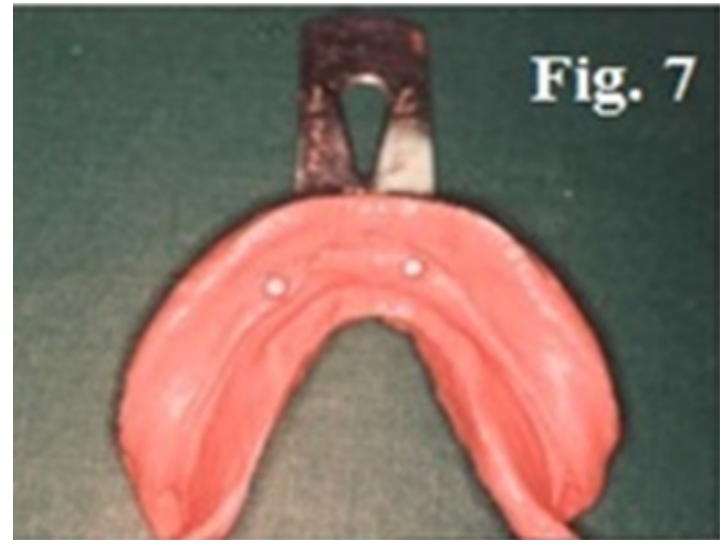

Figure 7 Irreversible hydrocolloid primary impression.

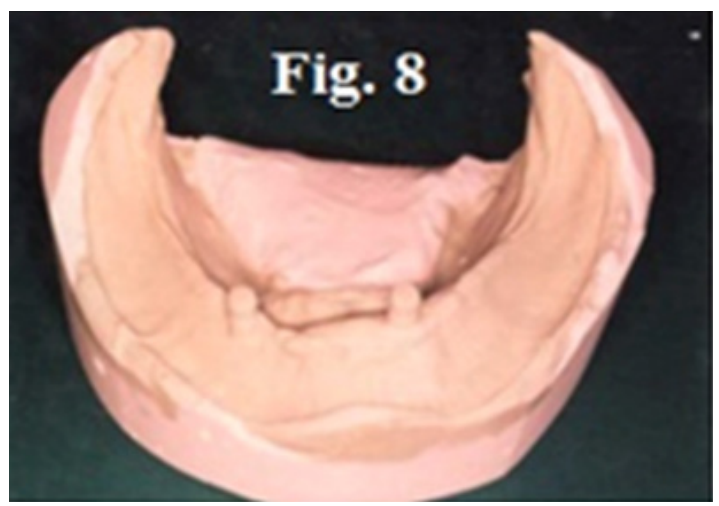

Figure 8 Study model.

Citation: Hameed NASA. Inserting retention plastic caps to ball implant supported overdenture: easy chair side technique.J Dent Health Oral Disord Ther. 20I5;2(5):165-169. DOI: 10.15406/jdhodt.2015.02.00064 


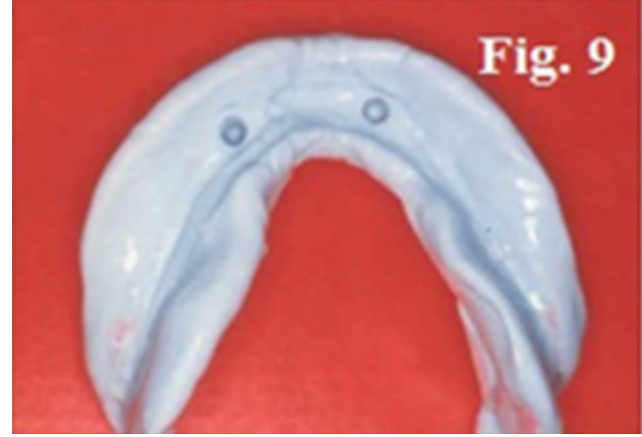

Figure 9 Regular body rubber base final impression.

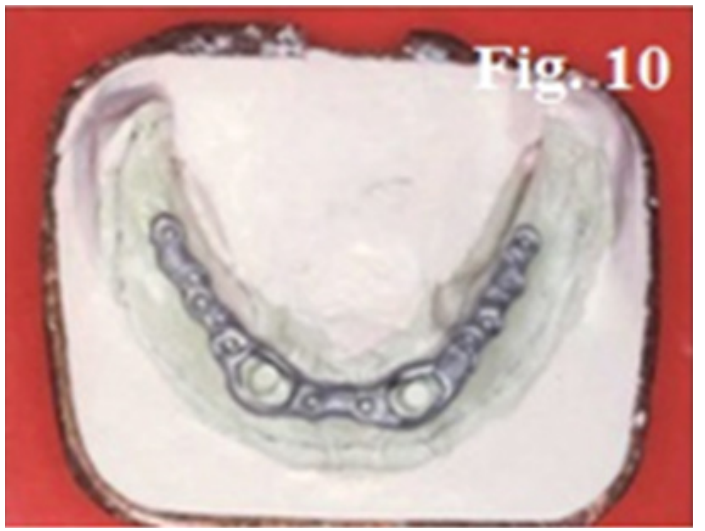

Figure 10 Vitallium framework (note that metal did no cover the implant abutments).

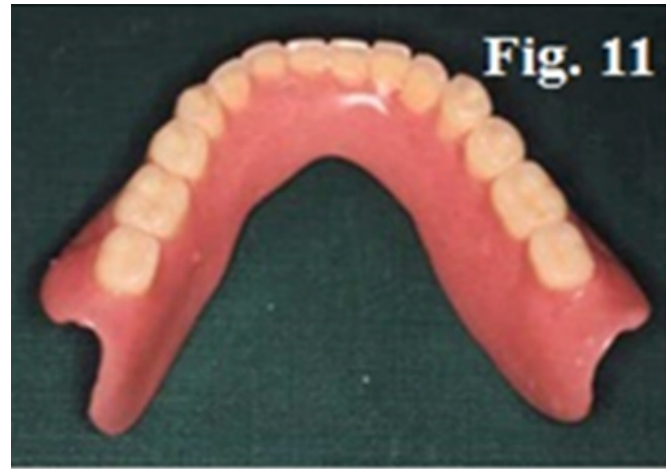

Figure II The finished over denture before attachment.

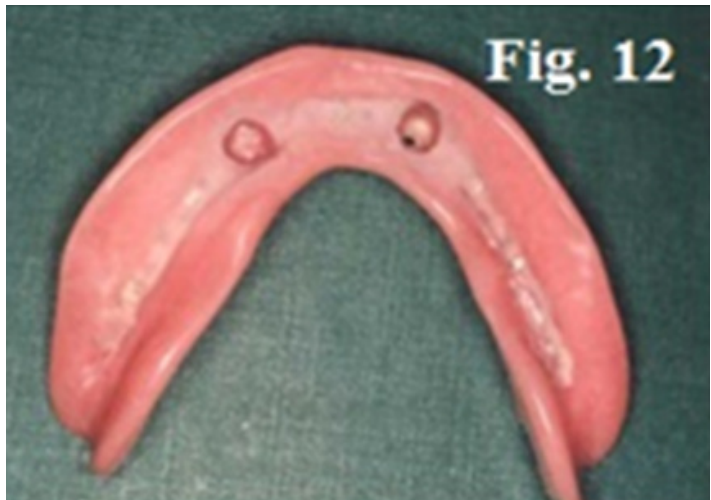

Figure 12 The finished over denture before attachment incorporation (impression surface). Spaces within abutment regions are widened.

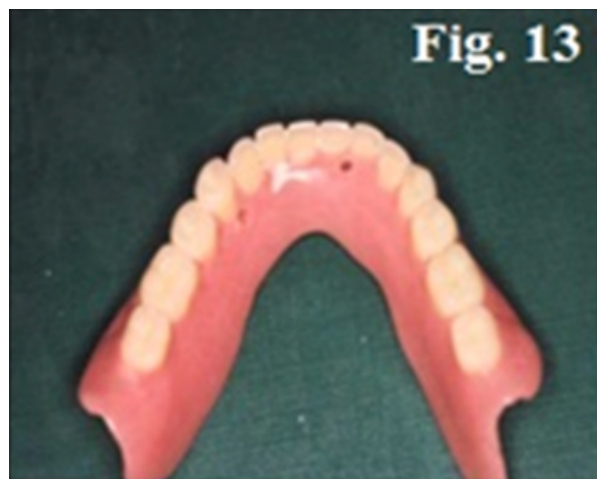

Figure 13 Lingual windows are prepared through thedenture.

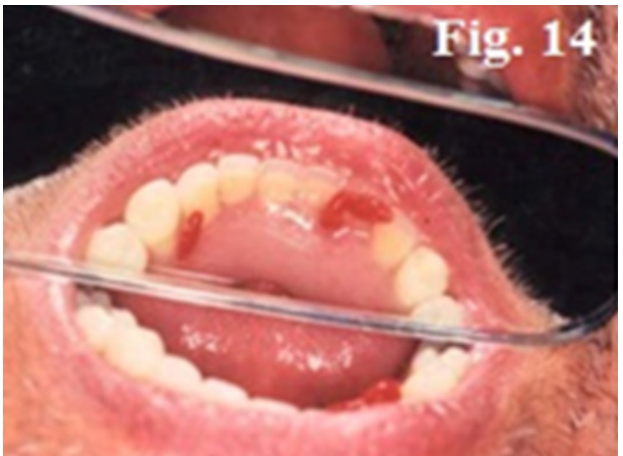

Figure I4 Excess cold-cure resin comes through the windows after incorporating retention plastic caps under biting force of the patient.

\section{Attachment incorporation}

a. The internal spaces within the abutment regions of the overdenture are widened and should exit lingually through the flange or superior surface (not in the area of a tooth) to vent excess acrylic resin (Figure $12 \& 13$ ).

b. With a small brush, paint cold-curing resin to the side and top of the housing. Wet acrylic recess in denture with cold-curing liquid. Mix cold-curing acrylic resin and paint into recesses of the overdenture.

c. Seat the denture over the abutments, asks the patient to bite in centric occlusion and allow the acrylic to cure.

d. After setting of the acrylic resin, the excess coming through the windows (Figure 14) is removed and the denture is polished at these areas (Figure 15).

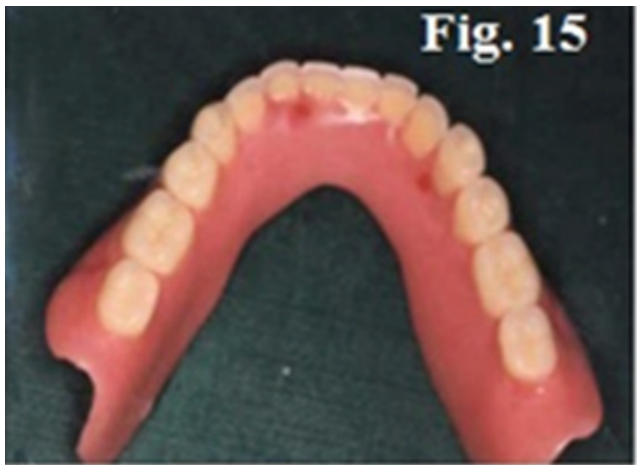

Figure I5 Excess acrylic resin is trimmed and polished. 
e. The finished over denture (tissue surface) after attachment incorporation (Figure 16).

f. Remove all orthodontic elastic rings that were used to block out undercuts around the abutments and insert the denture into patient's mouth (Figure 17).

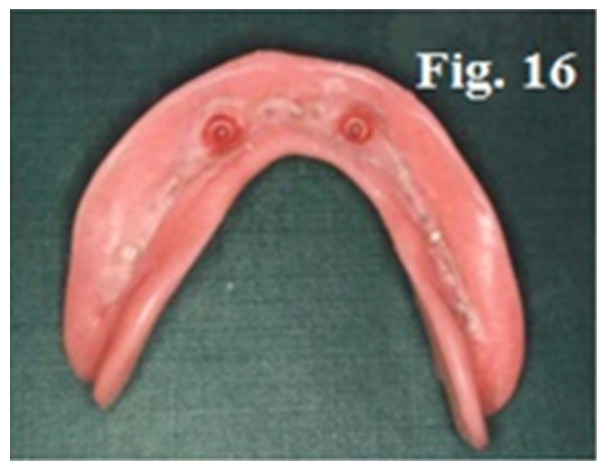

Figure 16 Finished over denture after attachment incorporation (tissue surface).

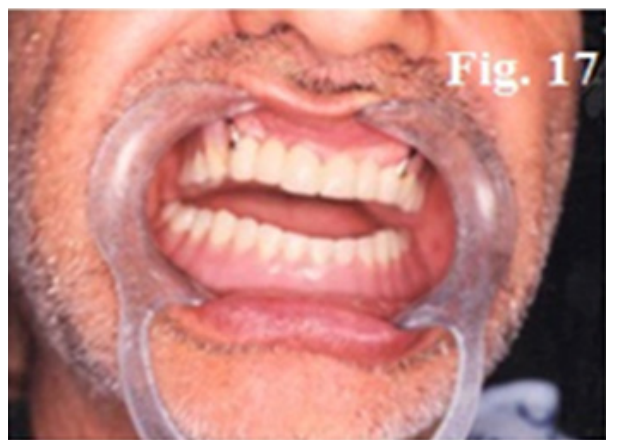

Figure 17 Finished implant retained over denture inside patient's mouth.

\section{Discussion}

This patient was referred to the dental center King Fahd Hospital, Al-Madinah Al-Menwara. K.S.A., to receive an overdenture, this was because the implanting dentist was working in a private clinic. He left suddenly to his country without completing the prosthetic part. The center was not equipped with facilities for such restorations at that time. The patient was asked to purchase the retention plastic caps, and by trial and error it was possible to complete the case with the current technique by the simple and available equipments. One of difficulties met was the absence of impression posts, implant body analogs, and the attachment-seating tool of the male portion. The current technique has solved these problems and an implant-supported overdenture was delivered to the patient. The present technique has the following advantages over the indirect one

a. Simplified prosthodontic procedures, encouraging a large number of practitioners with various levels of training and skills to consistently follow the prosthodontic protocol described.

b. Eliminating the need for extra laboratory procedures or instruments than that for the indirect method.

c. The retention plastic caps are inserted under the biting force of the patient. This produced precise passive fit of the overdenture on the implant, which leads to a dual benefit for prosthesis stability and atraumatic loading of the implant fixture. d. Avoidance of exposing the retention plastic caps to the curing temperature.

\section{Conclusion}

Fabrication of implant supported overdenture with retention plastic caps inserted using chair side technique is an advantageous treatment option because of saving cost and time, which benefits both the patient and the clinician.

\section{Acknowledgments}

None

\section{Conflicts of interest}

The author declares that there are no conflicts of interest.

\section{Funding}

None.

\section{References}

1. Adell R, Lekholm U, Rockler B, et al. A 15-year study of osseointegrated implants in the treatment of the edentulous jaw. Int J Oral Surg. 1981;10(6):387-416.

2. Boerrigter EM, Stegenga B, Raghoebar GM, et al. Patient satisfaction and chewing ability with implant-retained mandinular overdentures: a comparison with new complete denture with or without preprosthetic surgery. J Oral Maxillofac Surg. 1995;53(10):1167-1173.

3. Zarb GA, Schmitt A. The edentulous predicament, II: the longitudinal effectiveness of implant-supported overdentures. J Am Dent Assoc. 1996;127(1):66-72.

4. Feine JS, Carlsson GE, Awad MA, et al. The McGill consensus statement on overdentures. Mandibular two-implant overdentures as first choice standard of care for edentulous patients. Gerodontology. 2002;19(1):3-4.

5. Vercruyssen M, Marcelis K, Coucke W, et al. M Long-term, retrospective evaluation (implant and patient-centred outcome) of the two-implantssupported overdenture in the mandible. Part 1: survival rate. Clin Oral Implants Res. 2010;21(4):357-365.

6. Thomason JM, Kelly SA, Bendkowski A, et al. Two implant retained overdentures-a review of the literature supporting the McGill and York consensus statements. J Dent. 2012;40(1):22-34.

7. Takeshita S, Kanazawa M, Minakuchi S. Stress analysis of mandibular two-implant overdenture with different attachment systems. Dent Mater J. 2011;30:928-934.

8. Van Kampen F, Cune M, Van Der Bilt A, et al. Retention And Postinsertion Maintenance Of Bar-Clip, Ball And Magnet Attachments In Mandibular Implant Overdenture Treatment: An In Vivo Comparison After 3 Months Of Function. Clin Oral Implants Res. 2003;14(6):720-726.

9. Schwartzman B, Mito RS, Caputo AA, et al. Load transfer by multiple implants under various prosthetic devices (abstract). J Dent Res. 1991;70:460.

10. Jemt $\mathrm{T}$, Carlsson $\mathrm{L}$, Boss A, et al. In vivo load measurements on osseointegrated implants supporting fixed or removable prostheses: a comparative pilot study. Int J Oral Maxillofac Implants. 1991;6(4):413417.

11. Davidoff SR, Steinberg MA, Halpern A. The implant supported overdenture: a practical implant-prosthetic approach. Compend Contin Educ Dent. 1993;14:722. 
12. Zitzmann NU, Marinello CP. A review of clinical and technica considerations for fixed and removable implant prostheses in the edentulous mandible. Int J Prosthodont. 2002;15(1):65-72.

13. Naert I, Quirynen M, Hooghe M, et al. A comparative prospective study of splinted and unsplinted Brånemark implants in mandibular overdenture therapy: A preliminary report. J Prosthet Dent. 1994;71(5):486-492.

14. Misch CE. Contemporary implant dentistry. 2nd ed. St. Louis (MO) Mosby; 1999.
15. Thayer HH, Caputo AA. Occlusal force transmission by overdenture attachments. Additional studies J Prosthet Dent. 1979;41(3):266-271.

16. Brewer A, Morrow R. Overdentures. St Louis: The CV Mosby Co; 1975.

17. Thayer HH, Caputo AA. Photoelastic stress analysis of overdenture attachments. J Prosthet Dent. 1980;45(6):611-617.

18. Naert I, Quirynen M, Theuniers G, et al. Prosthetic aspects of osseointegrated fixtures supporting overdentures. A 4-year report. $J$ Prosthet Dent. 1991;65(5):671-680. 